\title{
Effect of single dose intravenous zoledronic acid on bone mineral density in post-menopausal osteoporosis of Bangladeshi women
}

\author{
M Hossain $^{1}$, I H Chowdhury ${ }^{1}$, MA Emran ${ }^{2}$, AHMA Habib ${ }^{3}$,

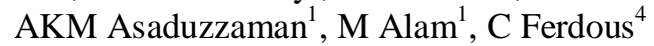 \\ ${ }^{I}$ Dept. of Anaesthesia, Analgesia \& Intensive Care Medicine, Bangabandhu Sheikh Mujib Medical University \\ Shahbag, Dhaka., ${ }^{2}$ Dept. of Physical Medicine \& Rehabilitation, Bangabandhu Sheikh Mujib Medical \\ University, Shahbag, Dhaka, ${ }^{3}$ OSD, DG Health, Mohakhali, Dhaka, \\ ${ }^{4}$ Bangladesh Institute of Health Science, Dhaka \\ E-mail: hossainbd07@gmail.com
}

\begin{abstract}
The osteoporosis is a major health threat that affects every third post-menopausal women. Postmenopausal osteoporosis is complicated with vertebral, femoral or radius fracture. This prospective study on post-menopausal osteoporosis was carried out in the Pain Centre, Department of Anaesthesia, Analgesia and Intensive Care Medicine of BSMMU, Dhaka during the period of January 2008 to January 2010. The post-menopausal women with back pain were screened by spinal radiographs and dual-energy X-ray absorptiometry (DXA) of lumbar spine to determine the bone mineral density (BMD). The woman after menopause with a BMD T-score of -2.5 or less with or without evidence of vertebral fracture is considered as post-menopausal osteoporosis. A total of 55 post-menopausal osteoporotic patients were assigned to receive a single dose of IV infusion of zoledronic acid $(5 \mathrm{mg})$ along with dietary calcium and vitamin-D. The spinal radiographs and dual-energy X-ray absorptiometry (DXA) were repeated in all the 55 patients at 12 months following zoledronic acid infusion. The mean BMD of lumbar spine increased significantly from pre-infusion value of $0.75695 \mathrm{~g} / \mathrm{cm}^{2}$ to post-infusion of $0.80216 \mathrm{~g} / \mathrm{cm}^{2}$. The T-score also increased from pre infusion value of $-3.567 \pm 0.77$ to $-3.158 \pm 0.08$ in 12 months following the infusion $(\mathrm{P}<0.01)$. The increase is $5.026 \%$ higher than pre infusion values. The spinal radiographs taken before infusion of zoledronic acid, showed 14 fractures. There was no new fracture in any case during the 12 months study period. So, it can be concluded that once yearly IV infusion of zoledronic acid is associated with a significant increase in BMD and decrease in the risk of vertebral fracture.
\end{abstract}

\section{Introduction}

Menopause is the period during which systemic estrogen level is reduced. During post-menopausal period, bone-remodeling cycle is distorted and is occasionally associated with low bone mass which is the major determinant of bone strength. Osteoporosis is characterized by reduced bone mass, which is related to decreased bone mineral density (BMD) and is accompanied by an increased risk of fracture ${ }^{1,2}$. In normal condition, the osteoclasts break and remove bone matrix. This is followed by a migration of osteoblasts to the resorption site causing new bone formation and maintains overall bone mass and stability. In osteoporosis, osteoclast formation is favored over osteoblast activity causing more bone resorption than its formation ${ }^{3}$. Every third women after menopause suffers from osteoporosis ${ }^{4}$.

Osteoporosis is often misdiagnosed and undertreated as its clinical presentations are variable.
Some patients do not have any obvious symptom; others suffer from acute back pain with kyphoscoliosis and loss of height which is usually related to vertebral or hip fracture ${ }^{5}$. Most common diagnostic criteria of osteoporosis is the BMD Tscore which is the number of standard deviations (SD) between the patient's BMD and the mean BMD value for a young healthy adult. A negative $\mathrm{T}$-score indicates that the BMD of the patient is lower than normal value. In 1994, World Health Organization (WHO) divided low BMD into the following categories: BMD T- score more than -1 is considered normal $(>-1=$ normal $), \quad \mathrm{T}$-score between less than -1 to more than -2.5 is diagnosed as Osteopenia $(<-1$ and $>-2.5=$ osteopenia $)$ and $\mathrm{T}$ score at or below -2.5 is Osteoporosis (T-score $\leq-$ $2.5=$ osteoporosis). In addition, there is special osteoporotic group called Severe or Established Osteoporosis where patient is suffering from osteoporotic BMD values in the presence of one or more fragility fracture ${ }^{6}$. Dual-energy X-ray 
absorptiometry (DXA) is considered the gold standard for determination of $\mathrm{BMD}^{1,6}$. The major clinical consequence of osteoporosis is the fracture. The most common sites of fractures are - spine, hip and wrist causing disability and morbidity. More than half of white women will experience an ostroporotic fracture during their life time if left untreated. Many osteoporotic fracture of the spine remain undiagnosed; approximately two-third of vertebral fractures for example is not recognized ${ }^{7}$. Avoiding the first fracture is a critical goal as a prior vertebral fracture increases the risk of another vertebral fracture by 3 fold $^{8}$.

Bisphosphonates provide effective therapy for osteoporosis. The zoledronic acid is the most potent bisphosphonate available. A $4 \mathrm{mg}$ intravenous formulation of zoledronic acid is widely used to reduce skeletal events in patients with advanced cancer $^{9}$ and a $5 \mathrm{mg}$ intravenous dose is approved in many countries to treat paget's disease ${ }^{10}$. The zoledronic acid has a higher binding affinity for hydroxyapatite and is a more potent inhibitor for farnesyl diphosphate synthese and bone resorption than other bisphosphonate ${ }^{11}$. Most of the work with zoledronic acid was done on white postmenopausal women where the incidence of osteoporosis is very high. Studies on Bangladeshi Postmenopausal women with osteoporosis are almost nil, where if any, were the comparison between two drugs. Bangladesh is a country of temperate zone, where the socio-economic condition is different from other parts of the world. Most of the people here are suffering from gastro-intestinal tract problems. So, comparison of oral drugs with IV preparations may not always be a true reflection of the drugs. Zoledronic acid is the only IV preparation available among the bisphosphonates group. Besides this, patients are reluctant to continue the drug as a daily therapy for a very long time. So, the present study was designed to demonstrate the effect of single infusion of zoledronic acid in Bangladeshi women with post-menopausal osteoporosis (PMO). The secondary objectives were to determine whether they reduce the risk of vertebral, hip and other types of fractures.

\section{Materials and Methods}

This prospective study on post-menopausal osteoporosis (PMO) was carried out in the Pain Centre of the Department of Anaesthesia, Analgesia and Intensive Care Medicine of Bangabandhu Sheikh Mujib Medical University (BSMMU), Shahbag, Dhaka during the period of January 2008 to January 2010. A total 55 post- menopausal osteoporotic patients were participated in the study where bone mineral density (BMD) were measured before and one year after the infusion of zoledronic acid. The post-menopausal women who were at least 50 years old, where menopause has occurred at least five years previously, who were suffering from back pain with BMD T-score of -2.5 or less were eligible to participate in the study. Major exclusion criteria were - systemic estrogen treatment within previous 6 months, treatment with raloxifene, calcitonin, tibolone within 6 months prior to the study, previous treatment with bisphosphonates within the last two years, previous use of parathyroid hormone, sodium fluoride, strontium ranelata, anabolic steroid or growth hormone within 6 months before entry, oral or IV systemic corticosteroid within 12 months, evidence of hepatic or renal diseases, disorder of parathyroid or thyroid glands, patient with malignant disease, patient with a creatinine clearance of less than $30.0 \mathrm{ml}$ per minute. The protocol was approved by the ethics committee and all the women gave written informed consent.

The osteoporosis was diagnosed by history, clinical examination, vertebral radiographs and measurement of bone mineral density BMD). The patients, who were presented with back pain, were screened initially by spinal radiographs. The vertebral radiographs were evaluated by an expert radiologist. The $\mathrm{X}$-ray showing a decrease in mineral density and an increase in prominence of vertical striations in the vertebral bodies or radiographs with one or more vertebral fracture or collapse were advised for bone mineral density (BMD) of lumbar spine. The BMD of the lumbar spines was measured by dual energy X-ray absorptiometry (DXA) scan. The patients with vertebral BMD T-score of -2.5 or less with or without evidence of vertebral fractures were selected to administer intravenous zoledronic acid. The creatinine clearance rate and serum calcium level were measured before the drug administration as creatinine clearance rate must be more than $30 \mathrm{ml}$ per minute and low serum calcium level is to be corrected with adequate dietary calcium.

A total of 55 patients were assigned to receive 15 minutes IV infusion of zoledronic acid $(5 \mathrm{mg})$. In addition, all patients received oral daily calcium (1000 mg per day) and vitamin D (400IU per day). Safety of the patients was evaluated by clinical evaluation of adverse events with telephonic interview and hospital visits. The vertebral radiographs and dual energy X-ray absorptiometry (DXA) were repeated at 12 months following infusion. The effects of zoledronic acid were 
determined by comparing the pre and post infusion values of BMD and its T-score.

All statistical analysis was pre-specified. The values of BMD before and after infusion of zoledronic acid were compared with the use of paired ' $t$ ' test. For all test a $\mathrm{P}$ value of 0.05 or less was considered to indicate statistical significance.

\section{Results}

The demographic characteristic of the 55 postmenopausal osteoporotic women who participated in the study are summarized in table I. All women were Bengali in race. The mean age of this women were 63.64 years. Table II shows the laboratory investigations which were required before infusion of zoledronic acid. These tests were repeated 10 days following infusion. The spinal radiographs, taken before infusion of zoledronic acid showed 14 fractures. No new fracture was found in follow up $\mathrm{X}$-ray, which is measured 12 months following infusion (Table III).

The mean bone mineral density (BMD) of the lumbar spine before infusion of zoledronic acid was $0.75695 \pm 0.09 \mathrm{~g}$ per $\mathrm{cm}^{2}$ (Table - IV), which corresponded to T-score of $-3.567 \pm 0.77$ (Table$\mathrm{V})$. All the women received zoledronic acid $(5 \mathrm{mg})$ regimens. The mean BMD after one year increased to $0.80216 \pm 0.08 \mathrm{~g}$ per $\mathrm{cm}^{2}$ (Table $\left.-\mathrm{IV}\right)$, which corresponded to T-score of $-3.158 \pm 0.08$ (Table- V). The increase of BMD is about $5.026 \%$ higher than the pre-infusion values (Table-IV). The increase in BMD is statistically significant (Table - VI).

Table I: Demographic characteristics of the patients

\begin{tabular}{lc}
\hline \multicolumn{1}{c}{ Variable } \\
\hline Number of patients & 55 \\
Race & Bengali \\
Age in years: & \\
$\quad$ Mean & 63.64 \\
Weight in kg & \\
$\quad$ Mean & 57.40 \\
\hline
\end{tabular}

Table II: Laboratory investigations before and 10 days following infusion

\begin{tabular}{lll}
\hline \multicolumn{1}{c}{ Variable } & $\begin{array}{c}\text { before infusion } \\
\text { (baseline) }\end{array}$ & $\begin{array}{c}10 \text { days after } \\
\text { infusion }\end{array}$ \\
\hline S. Calcium & $2.5 \mathrm{mmol} / \mathrm{L}$ & $2.4 \mathrm{mmol} / \mathrm{L}$ \\
Creatinine clearance rate & $45.5 \mathrm{ml} / \mathrm{min}$ & $40.7 \mathrm{ml} / \mathrm{min}$ \\
Serum creatinine & $0.86 \mathrm{mg} / \mathrm{dl}$ & $1.10 \mathrm{mg} / \mathrm{dl}$ \\
\hline
\end{tabular}

Table III: Comparison of number of fractures in radiographs before and 12 months following infusion of zoledronic acid.

\begin{tabular}{lccc}
\hline Variable & $\begin{array}{c}\text { before infusion } \\
\text { (base line) }\end{array}$ & $\begin{array}{c}12 \text { months } \\
\text { after infusion }\end{array}$ & $\begin{array}{c}\% \\
\text { increased }\end{array}$ \\
\cline { 1 - 3 } $\begin{array}{l}\text { Number of } \\
\text { fractures in }\end{array}$ & 14 & 14 & 0 \\
Radiographs & & & \\
\hline
\end{tabular}

Table IV: Increase in bone mineral density $\left(\mathrm{g} / \mathrm{cm}^{2}\right)$ : before and 12 months following infusion of zoledronic acid.

\begin{tabular}{lccc}
\hline Variable & $\begin{array}{c}\text { Before infusion } \\
\text { (base line) } \\
(\text { Mean } \pm \text { SD) }\end{array}$ & $\begin{array}{c}12 \text { months after } \\
\text { infusion } \\
(\text { Mean } \pm \text { SD) }\end{array}$ & $\begin{array}{c}\% \\
\text { increased }\end{array}$ \\
\hline Mean & $0.75695 \pm 0.09$ & $0.80216 \pm 0.08$ & 5.026 \\
\hline
\end{tabular}

Table V: T-score: before and 12 months following infusion of zoledronic acid.

\begin{tabular}{lcc}
\hline Variable & $\begin{array}{c}\text { Before infusion (base line) } \\
(\text { Mean } \pm \text { SD) }\end{array}$ & $\begin{array}{c}12 \text { months after infusion } \\
(\text { Mean } \pm \text { SD) }\end{array}$ \\
\hline Mean & $-3.567 \pm 0.77$ & $-3.158 \pm 0.80$ \\
\hline
\end{tabular}

Table VI: Comparison of BMD and its T-score before and 12 months following infusion. Values are regarded significant if $\mathrm{P}$ $<0.05$.

\begin{tabular}{lcccc}
\hline Variable & $\begin{array}{c}\text { Before infusion } \\
\text { (baseline) } \\
\text { (Mean } \pm \mathrm{SD})\end{array}$ & $\begin{array}{c}12 \text { months } \\
\text { after infusion } \\
(\text { Mean } \pm \mathrm{SD})\end{array}$ & $\mathrm{t}$-value & $\mathrm{p}$ - value \\
\hline BMD & $0.75695 \pm 0.09$ & $0.80216 \pm$ & -2.635 & 0.010 \\
$\left(\mathrm{~g} / \mathrm{cm}^{2}\right)$ & & 0.08 & & \\
$\mathrm{BMD}$ & $-3.567 \pm 0.77$ & $-3.158 \pm 0.08$ & -2.712 & 0.008 \\
T-score & & & & \\
\hline
\end{tabular}

\section{Discussion}

The treatment of post-menopausal osteoporosis with intravenous infusion of zoledronic acid caused increase in bone mineral density, that are similar to those observed with daily oral bisphosphanate therapy. The zoledronic acid increased the spinal bone mineral density at 12 months to $5.026 \%$ above the values found before drug administration. This increase can be compared with $5 \%$ increase with a daily $10 \mathrm{mg}$ dose of alendronate ${ }^{12}, 3 \%$ increase with daily $5 \mathrm{mg}$ dose of risedronate ${ }^{13}$ or $5 \%$ increase with a daily $150 \mathrm{mg}$ dose of pamidronate ${ }^{14}$. But the efficacy of these therapies is sometimes compromised by low rates of adherence and persistence. In one study it is indicated that within one year of initiating treatment for osteoporosis, $45 \%$ of the patients do not continue to fill their prescriptions ${ }^{15}$. Poor adherence is associated with significant level of fracture rate ${ }^{16}$. Our study indicates that the increase in bone density is greater than that found in the previous oral study $(5.026 \%)$. Our study also indicates that much longer dosing intervals are compatible with efficacy (in terms of increase in bone density). Increase in bone density at 12 months signifies that bone formation is greater than the bone resorption or in other word, bone turnover is suppressed. Lindsay $\mathrm{R}$, et al. estimated that $20 \%$ of women who have had a vertebral fracture will experience another fracture within 1 year $^{17}$. But in our study there were 14 fractures at the entry into the study and at 12 months of the infusion there was no new fracture. This signifies that the zoledronic acid caused more bone formation than the bone resorption. So, 
Lindsay R, et al. suggested to provide prompt therapy to the patient with fracture. Rapid and sustained normalizing of bone turnover in patient with osteoporosis has the potential to prevent bone loss and may reduce fracture.

Osteoporosis has been regarded as requiring daily therapy and maintaining compliance with daily regimens. Once yearly therapy guarantees adherence and persistence for 12 months and ensure yearlong bone protection in postmenopausal osteoporosis. So, it can be concluded that zoledronic acid ensures adherence over twelve months and provides as a promising drug for the Bangladesh postmenopausal women suffering from osteoporosis.

\section{References}

1. International Osteoporosis Foundation. Http://www.iofbonehealth.org/health-professionals. html. Accessed September 12, 2007.

2. NIH Consensus Development Panel on Osteoporosis Prevention, Diagnosis, and therapy. Osteoporosis prevention, diagnosis, and therapy. JAMA 2001; 285:785-95.

3. Consensus development conference. Diagnosis, prophylaxis and treatment of osteoporosis. Am J Med 1991; 90: 170-210.

4. O'Neill TW. Looking back: developments in our understanding of the occurrence, aetiology \& prognosis of osteoporosis over the last 50 years. Rheumatology 2005; 44: 33- 35 .

5. Siris ES, Miller PD, Barrett-Connor E, et al. Identification and fracture outcomes of undiagnosed low bone mineral density in postmenopausal women. Results from the National Osteoporosis Risk Assessment. JAMA 2001; 286: 2815-22.

6. World Health Organization Study Group. Assessment of fracture risk and its application to screening for postmenopausal osteoporosis, Geneva: World Health Organization; 1994. WHO Technical Report Series 843.

7. Meunier PJ, Delmas PD, Eastell R, et al. Diagnosis and management of osteoporosis in postmenopausal women: clinical guidelines. Clin Ther 1999; 21: 102544.

8. Lindsay R, Silverman SL, Cooper C, et al. Risk of new vertebral fracture in the year following a fracture. JAMA 2001; 285: 320-3.

9. Perry CM, Figgett DP. Zoledronic acid: a review of its use in patients with advanced cancer. Drugs 2004; 64: 1197-211.

10. Reid IR, Miller P, Lyles K, Fraser W, Brown JP, Saidi $\mathrm{Y}$, et al. Comparison of a single infusion of zoledranic acid with residronate for Paget's disease. N Engl J Med 2005; 353: 898-908.

11. Dunford JE, Thompson K, Coxon FP, Luckman SP, Hahn FM, Poulter CD, et al. Structure - activity relationships for inhibition of farnesyl disphosphate synthase in vitro and inhibition of bone resorption in vivo by nitrogen-containing bisphosphonates. J Pharmacol Exp Ther 2001; 296:235-42.

12. Liberman UA, Weiss SR, Broll J, et al. Effect of oral alendronate on bone mineral density and the incidence of fractures in postmenopausal osteoporosis. N Engl J Med 1995; 333: 1437-43.

13. Harris ST, Watts NB, Genant HK, et al. Effects of risedronate treatment on vertebral and non-vertebral fractures in women with postmenopausal osteoporosis: a rendomized controlled trial. JAMA 1999; 282: 1344-52.

14. Reid IR, Wattie DJ, Evans MC, Gamble GD, stapleton JP, Cornish J. Continuous therapy with pamidronate, a potent bisphosphonate, in postmenopausal osteoporosis. J Clin Endocrinol Metab 1994; 79: 1595-9.

15. Solomon DH, Avorn J, Katz JN, et al. Compliance with osteoporosis medications. Arch Intern Med 2005; 165: 2414-9.

16. Siris ES, Harris ST, Rosen CJ, et al. Adherence to bisphosphonate therapy and fracture rate in osteoporotic women: relationship to vertebral and nonvertebral fractures from 2 US claims databases. Mayo Clini Proc 2006; 81: 1013-22.

17. Lindsay R, Silverman SL, Cooper C, hanley DA, Barton I, Broy SB, et al. Risk of new vertebral fracture in the year following a fracture. JAMA 2001; 285: 320-3. 